\title{
Psychosocial and economic profile of a sample of families with thalassaemic children in Lebanon
}

\author{
VAZKEN M DER KALOUSTIAN*, ADELEKHUDR*, SALIM FIRZLI†, \\ AND IBRAHIM DABBOUS† \\ From the *National Unit of Human Genetics and †Department of Paediatrics, American University of Beirut \\ Medical Center, Beirut, Lebanon.
}

SUMmaRY Thalassaemia major is a relatively common disease in Lebanon. This study of 41 families with 54 patients attending the American University of Beirut Medical Center was conducted to define some aspects of the disease in Lebanon and to assess the attitudes of affected families on relevant psychosocial and economic issues. We conclude that because of the high frequency of consanguineous marriage, thalassaemia major is more common in Lebanon than might be expected on the basis of the incidence of the trait. Most patients are diagnosed early in life, but their treatment is generally far from adequate; securing desferrioxamine and paying for follow up visits to the doctor seem to be the most important financial burdens. The general population of the country is not properly informed yet and about $70 \%$ of the families had not heard about the disease before having an affected child. The inherited nature of the disease is not clear in the minds of a high percentage of the families, and in about $30 \%$ of cases the family had not been told about the advisability of screening to detect heterozygotes. The great majority of families favour a preventive approach to thalassaemia, based on heterozygote screening and the possibility of prenatal diagnosis.

In Lebanon, 2 to $3 \%$ of the population of around 3.5 million carry the $\beta$ thalassaemia mutation. ${ }^{1}$ Moreover, consanguineous marriages are found in more than $20 \%$ of the families, reaching $40 \%$ in certain communities. ${ }^{2}$ Consequently, the birth rate of infants with $\beta$ thalassaemia major is estimated to be around $0 \cdot 4 / 1000$. The total number of living patients in Lebanon is estimated to be around 300 . The recommended treatment for thalassaemia major consists of regular blood transfusions to keep the haemoglobin level above about $11 \mathrm{~g} / \mathrm{dl}$ and subcutaneous infusion of the iron chelating drug desferrioxamine in a dose of 35 to $50 \mathrm{mg} / \mathrm{kg} / \mathrm{day} .^{3}$ This drug costs between $\$ 6$ and $\$ 12$ per gram depending on the country and the method of obtaining it. The families have to pay for most of their medical treatment, and the disease therefore imposes serious financial, as well as social and psychological, burdens on the patients, their families, and the medical community at large. The present study was conducted to evaluate some aspects of these burdens, to assess the knowledge of the disease among the affected families, and to find out their attitudes to prenatal diagnosis for the condition.

Received for publication 2 August 1986.

Revised version accepted for publication 12 November 1986

\section{Methods}

Forty-four families with $57 \beta$ thalassaemic children were interviewed and a questionnaire was completed grading various problems presented by the

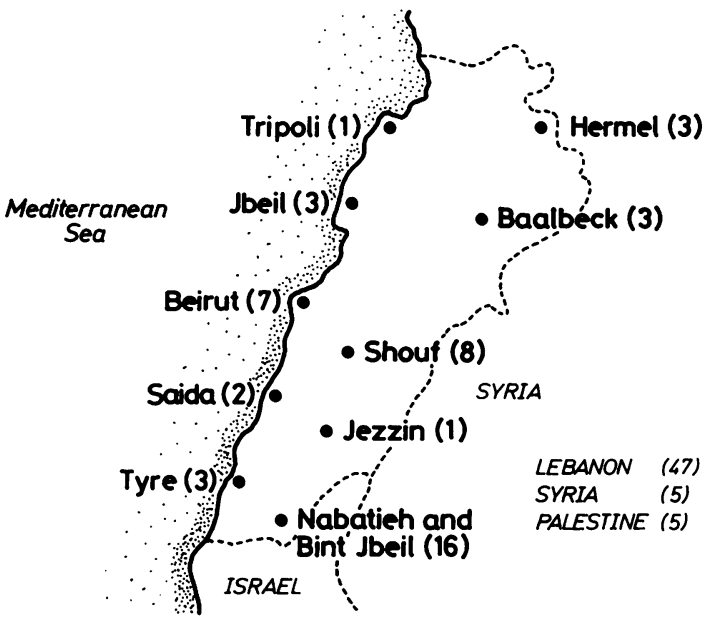

FIG 1 Geographical distribution of patients by town of origin. 
disease according to the families' perceptions of their importance. The patients were attending the Paediatric Haematology Clinic of the Outpatient Department of the University of Beirut Medical Center, which is situated in West Beirut and serves a population belonging mainly to the Moslem community.

\section{Results}

The patient group included 32 males and 25 females. Fig 1 shows their geographical origin by district of birth and fig 2 shows their age at the time of the interview. Table 1 gives their distribution according to their religious/ethnic community. Table 2 summarises their socioeconomic level, based on the income and occupations of the father.

Table 3 gives the sibship size and birth order in the families, listed according to the mother's age, from the youngest to the oldest. It includes information on the use of contraceptives before and after the diagnosis of the first affected child and on attitudes to prenatal diagnosis.

The early age at presentation (fig 3) generally indicates a severe form of $\beta$ thalassaemia. Thirtyfive of the patients had had their spleen removed, mostly before the age of five years (fig 4). The early age at splenectomy reflects the low transfusion scheme followed in the past. Information on the level of the haematocrit at the time of transfusion could be obtained for 45 patients. Even today, only four patients were transfused in the recommended way at a haematocrit of $30 \%(=\mathrm{Hb} 10 \mathrm{~g} / \mathrm{dl})$; in most the haematocrit was allowed to fall to lower levels, in many cases as low as $20 \%(=\mathrm{Hb} 7 \mathrm{~g} / \mathrm{dl})$.

The families were asked to classify the financial burden imposed by five defined aspects of the treatment, in order from 1 (highest) to 5 (lowest). Table 4 summarises the responses in relation to social class. Only a minority of the families can obtain desferrioxamine for their children, but the attempt to do so is not determined only by social class. For most of the families who pay for the drug themselves, this is the greatest financial burden of the disease.

Only eight of the 44 families had ever heard of thalassaemia before the diagnosis of their first affected child, and even now only 21 are completely clear about the inherited nature of the disease. Twenty-six families had undergone screening for

TABLE 1 Distribution according to religious/ethnic community.

\begin{tabular}{llcc}
\hline & & Families & Patients \\
\hline Moslems & Sunnites & 15 & 19 \\
& Shiites & 22 & 27 \\
Christians & Druzes & 1 & 2 \\
& Maronites & 3 & 3 \\
\multirow{3}{*}{ Total } & Greek Orthodox & 2 & 4 \\
& Greek Catholic & 1 & 2 \\
\hline
\end{tabular}

TABLE 2 Distribution of families according to socioeconomic level.

\begin{tabular}{ll}
\hline Socioeconomic level & No of families \\
\hline Lower & 21 \\
Middle & 11 \\
Upper & 12 \\
\hline
\end{tabular}

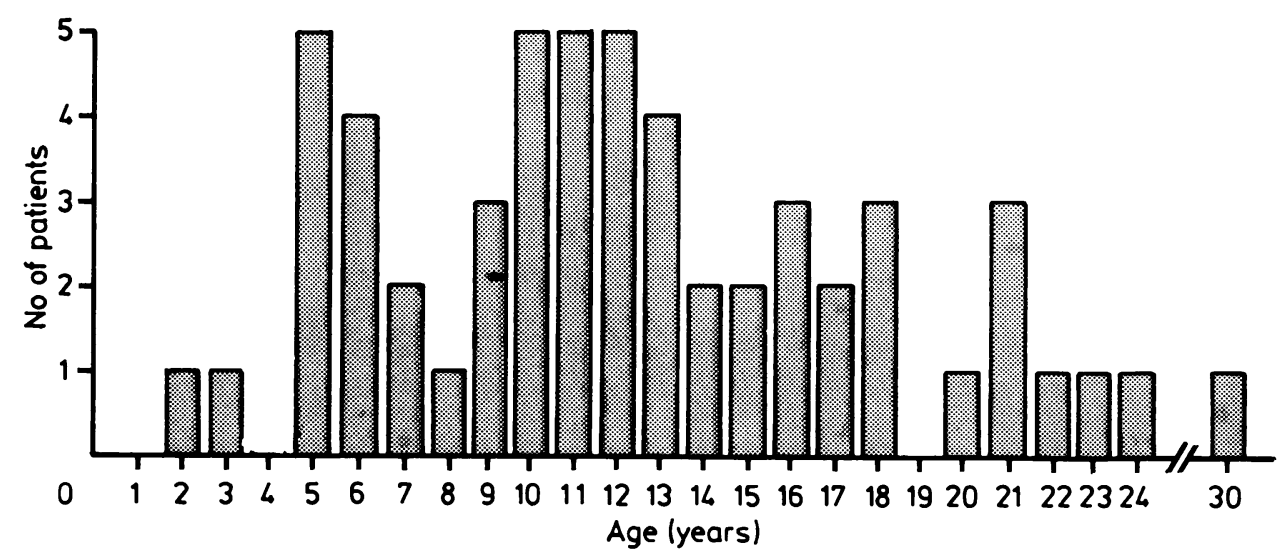

FIG 2 Distribution according to age of patient at the time of the interview. 


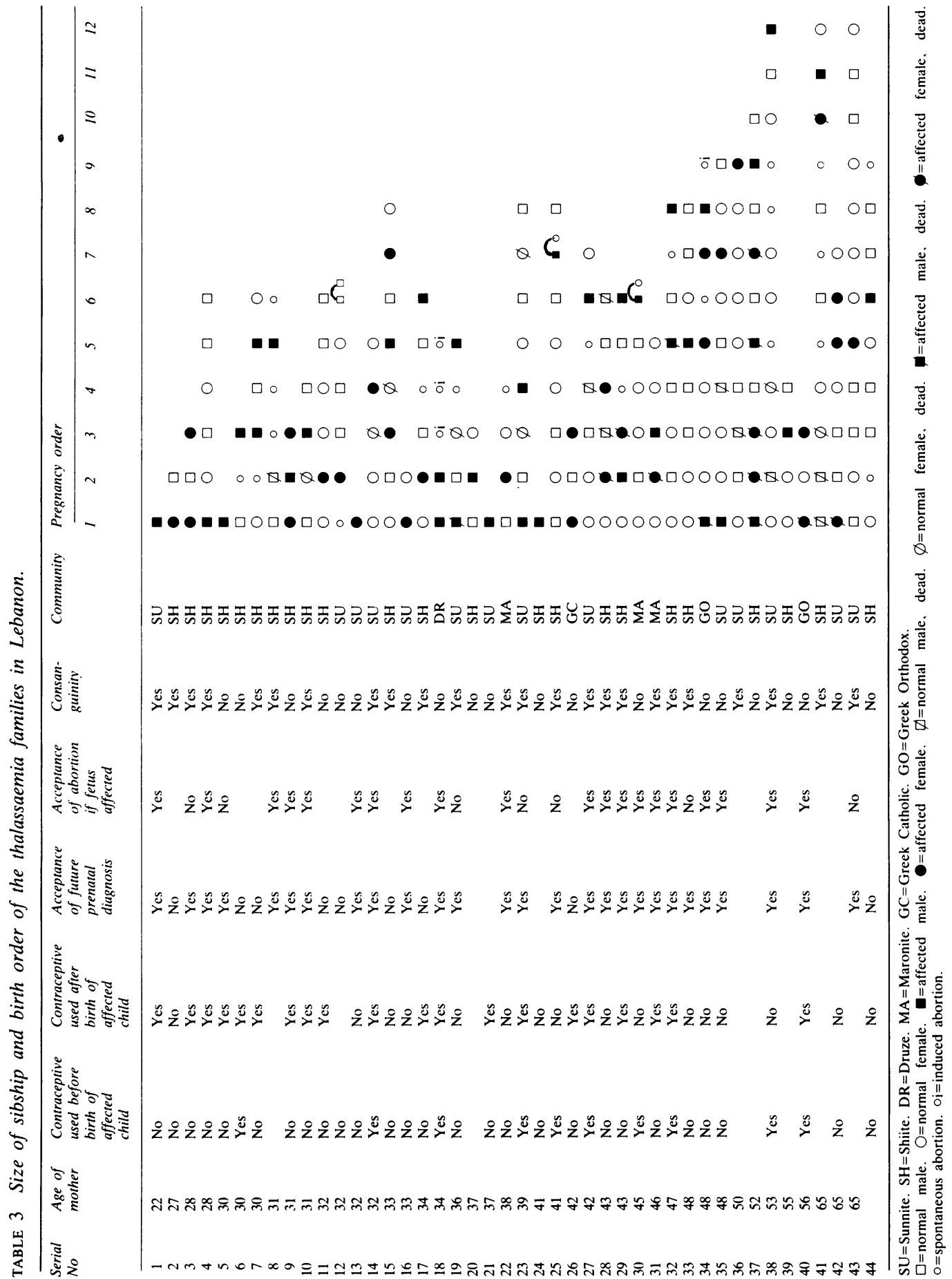




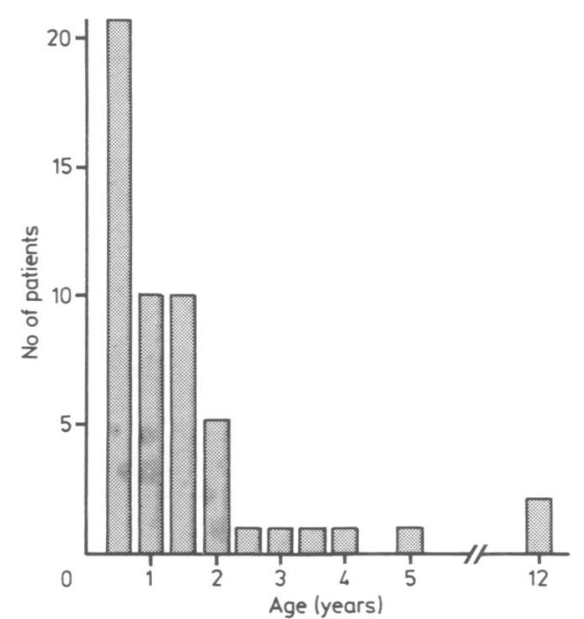

FIG 3 Distribution of the patients according to age at the time of diagnosis. heterozygote detection, but eight had not, even though they were aware of the possibility and the indications. Nine families had not been screened and did not know it was possible. One family gave no answer.

The order of importance of certain aspects of the distress caused by the disease fell into three patterns (table 5) which varied somewhat according to socioeconomic level and access to desferrioxamine. The high ranking given to fear of early death is to be expected when desferrioxamine treatment is beyond the reach of so many families.

The answers to the following questions on social attitudes to the disease are summarised in table 6 .

Do you feel embarrassed if your neighbours and friends know about your child's illness?

Do you discourage discussion of the illness at home?

Would you like your child to have appropriate information about his/her illness?

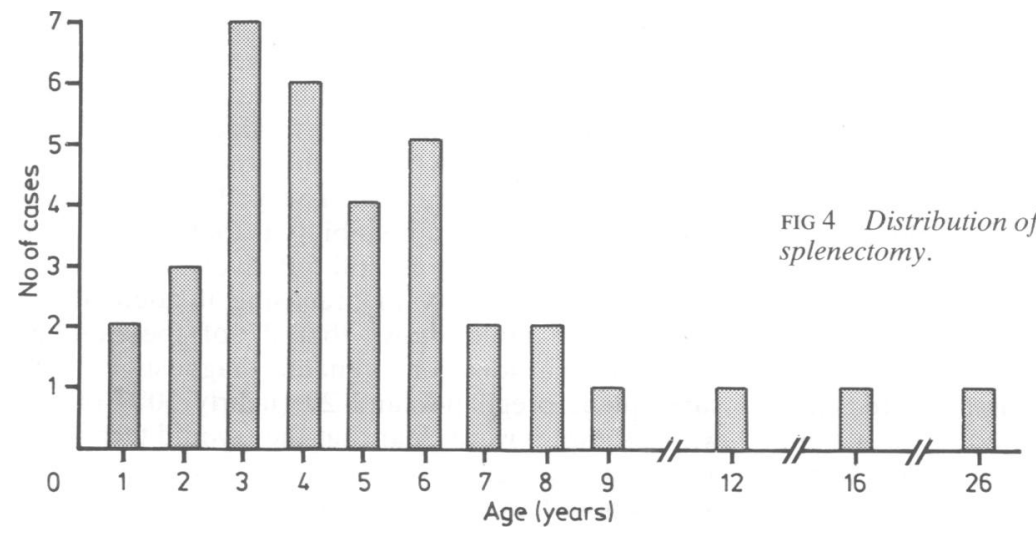

TABLE 4 Patterns of financial burden on family.

\begin{tabular}{|c|c|c|}
\hline $\begin{array}{l}\text { Pattern A (12 families) (desferrioxamine } \\
\text { paid for by family) }\end{array}$ & $\begin{array}{l}\text { Pattern B (23 families) (desferrioxamine } \\
\text { not used) }\end{array}$ & $\begin{array}{l}\text { Pattern C (4 families) (desferrioxamine } \\
\text { provided free of charge) }\end{array}$ \\
\hline $\begin{array}{l}\text { (1) Desferrioxamine } \\
\text { (2) Transfusion } \\
\text { (3) Visits to the doctor } \\
\text { (4) Admission to hospital } \\
\text { (5) Blood }\end{array}$ & $\begin{array}{l}\text { (1) Visits to the doctor } \\
\text { (2) Admission to hospital } \\
\text { (3) Transfusion } \\
\text { (4) Blood }\end{array}$ & $\begin{array}{l}\text { (1) Visits to the doctor } \\
\text { (2) Admission to hospital } \\
\text { (3) Transfusion } \\
\text { (4) Blood }\end{array}$ \\
\hline \multicolumn{3}{|l|}{ Socioeconomic level } \\
\hline $\begin{array}{l}\text { Low } \\
\text { Middle } \\
\text { High } \\
\text { Total }\end{array}$ & $\begin{array}{r}12 \\
7 \\
4 \\
23\end{array}$ & $\begin{array}{l}3 \\
0 \\
1 \\
4\end{array}$ \\
\hline
\end{tabular}


TABLE 5 Patterns showing the order of importance of the distressing aspects of the disease.

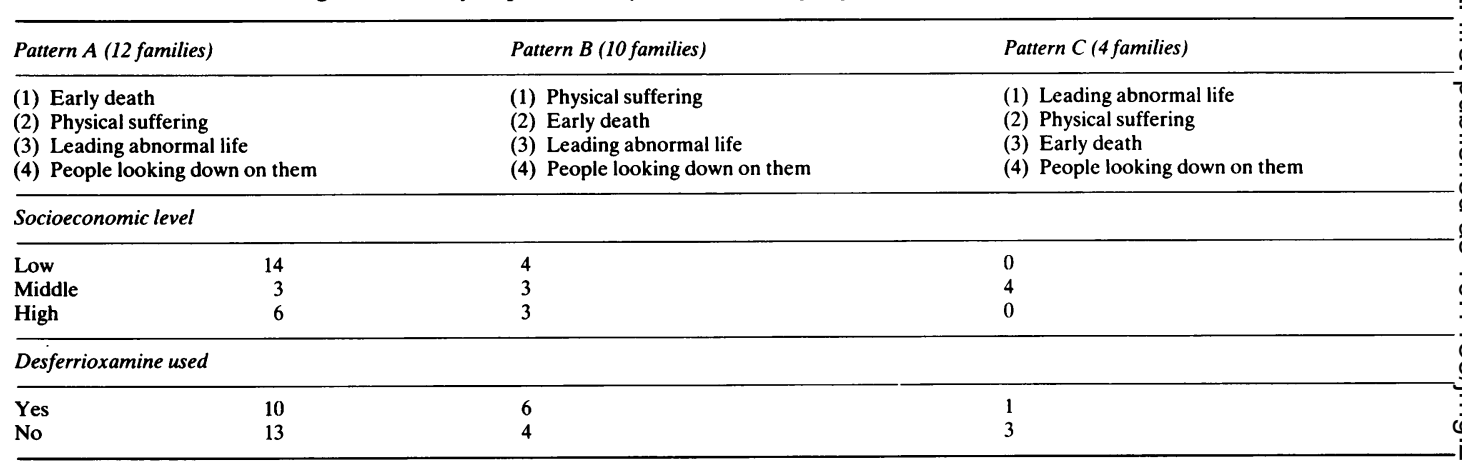

There was no significant difference in the attitudes of the families according to their socioeconomic level.

Table 7 presents the answers to the question, 'Would you request prenatal diagnosis in your next pregnancy?' according to the religious adherence of the respondents.

\section{Discussion}

Though the 44 families interviewed originated from areas all over Lebanon, 38 of them were Moslem. This is because the American University of Beirut Medical Center is located in a sector of the city that caters predominantly for the Moslem population of the country.

Table 3 shows that the percentage of couples not using any contraception dropped sharply from $61 \%$ to $36 \%$ after the diagnosis of the first affected child. This change is unlikely to be related to the stage in their reproductive life, as it would be in western

TABLE 6 Some social attitudes of the 44 families.

\begin{tabular}{llll}
\hline & Yes & No & No answer \\
\hline Embarrassed if others know & 16 & 24 & 4 \\
Discourage discussion at home & 22 & 20 & 7 \\
Favour more information for their child & 20 & 17 & 7 \\
\hline
\end{tabular}

countries, because of the large final family size in $N$ Lebanon. However, the couples' answers relating to 응 the use of contraceptives do not necessarily correspond to the reality of their reproductive behaviour. For instance, in families $4,7,9,11,17,23,26,29$, 31 , and 40 , more than one pregnancy occurred after the birth of an affected child. One possible interpretation of this discrepancy is that, when the subsequent pregnancy occurred, the couple did ngt $\vec{\phi}$ yet have a clear idea of the inherited nature of the disease. Indeed, some of the families still did ne ${ }^{t}$. understand this at the time of this study, that is, the had not been informed in a way that they could understand. A second possibility is that, in a society where contraception is still relatively infrequent, $\mathbb{D}$ couples had difficulty in practising it adequately.

The same table shows that 27 of the families favoured the idea of prenatal diagnosis in any subsequent pregnancy and 20 (nearly $50 \%$ of the whole sample) were clear that they would terminate an affected pregnancy. Nine couples were completely opposed to prenatal diagnosis. (Four did noto answer and three were either divorced or not in a 3 condition to start a new pregnancy.) Table 7 , which presents the families' attitudes according to their religion, indicates that for severe genetic disease, prenatal diagnosis is an acceptable option for many families, even among a Moslem population.

Table 3 also shows that $55 \%$ of the parents of the

TABLE 7 Attitudes towards prenatal diagnosis and religion in the 36 families responding.

\begin{tabular}{|c|c|c|c|c|c|c|}
\hline \multirow{2}{*}{$\begin{array}{l}\text { Prenatal } \\
\text { diagnosis } \\
\text { acceptable }\end{array}$} & \multicolumn{6}{|c|}{ Community } \\
\hline & Sunnite & Shiite & Druze & Maronite & Other Christians & Total \\
\hline $\begin{array}{l}\text { Yes } \\
\text { No } \\
\text { Total }\end{array}$ & $\begin{array}{r}10 \\
1 \\
11\end{array}$ & $\begin{array}{r}11 \\
7 \\
18\end{array}$ & $\begin{array}{l}1 \\
1\end{array}$ & $\begin{array}{l}3 \\
3\end{array}$ & $\begin{array}{l}2 \\
1 \\
3\end{array}$ & $\begin{array}{r}27 \\
9 \\
36\end{array}$ \\
\hline
\end{tabular}


thalassaemic children were consanguineous. This is significantly higher than the figure for the general population (around $20 \%$ ) or for the Moslem communities (30\% among both Sunnites and Shiites and $40 \%$ among Druzes). ${ }^{2}$ Probably due to the high rate of consanguineous marriages, thalassaemia major is more common in Lebanon than might be expected from the frequency of the trait in the country.

Fig 3 shows that most of the patients were diagnosed before the age of two years. This indicates that most of them have thalassaemia major and that though thalassaemia intermedia occurs, it is relatively less common.

Table 4 shows that the cost of desferrioxamine is a major financial burden to the families who use it for their children. Out of 10 families with a high socioeconomic level, five buy desferrioxamine, while out of 18 families with a low socioeconomic level, only three can arrange to have desferrioxamine purchased, using a very high percentage of their income as well as contributions from relatives. These families just manage to treat their child, but with the tremendous rate of inflation in the economy of Lebanon since the spring of 1984, many will have to discontinue treatment. This situation emphasises the importance of prevention in Lebanon and other less developed parts of the world.

We thank Dr Bernadette Modell for her help and encouragement.

\section{References}

${ }^{1}$ Cabannes R, Taleb N, Ghorra F, Schmitt-Beurnier A. Etude des types hemoglobiniques dans la population du Liban. Nouv Rev Fr Hematol 1965;5:851-6.

2 Der Kaloustian VM, Naffah J, Loiselet J. Genetic diseases in Lebanon. Am J Med Genet 1980;7:187-205.

3 WHO Working Group. Hereditary anaemias: genetic basis, clinical features, diagnosis and treatment. Bull WHO 1982;60:643-60.

Correspondence and requests for reprints to $\mathrm{Dr}$ Vazken Der Kaloustian, Department of Medical Genetics, The Montreal Children's Hospital, 2300 Tupper Street, Montreal, Quebec H3H 1P3, Canada. 